\title{
RESPONSABILIDAD DERIVADA TRAS LA EXTINCIÓN DEL CONTRATO DE PUESTA A DisPOSICIÓN
}

\author{
Pablo PUENTE MARTÍNEZ \\ GRADUADO EN RELACIONES LABORALES y RECURSOS HuMANOS \\ UNIVERSIDAD DE LA RIOJA
}

SumARIO: I. Introducción: Evolución y causas del Contrato de Puesta Disposición. II. Marco legal de la cesión de trabajadores. II.I. Derecho supranacional. II.2. Derecho español. II.3. El Contrato de Puesta a Disposición. III. Responsabilidad tras la extinción del Contrato de Puesta a Disposición. III.I. Supuestos conflictivos. III.I.I. Extinción «ante tempus» del contrato de trabajo. III.I.2. Prestación de servicios en la empresa usuaria tras la extinción. III.I.3. Extinción tras la contratación sucesiva del trabajo mediante ETT. III.I.4. El supuesto del artículo I5.5 del Estatuto de los Trabajadores. III.I.5. Cláusula de prohibición de contratación del trabajador por la empresa usuaria. III.2. Responsabilidad contractual. III.3. Responsabilidad económica. III.3.I. Régimen de la responsabilidad económica. III.3.2. La garantía financiera de las Empresas de Trabajo Temporal. III.3.3. Responsabilidad salarial. III.3.4. Responsabilidad indemnizatoria. III.3.5. Responsabilidad de cuotas de Seguridad Social. IV. Otras consideraciones. IV.r. Representación de los trabajadores en la empresa usuaria. IV.2. La responsabilidad de las Administraciones Públicas. V. Conclusiones. VI. Bibliografía citada.

RESUMEN: Tras una breve revisión de la evolución histórica del empleo por medio de las empresas de trabajo temporal y del marco normativo sobre el que se asientan este tipo de relaciones de trabajo, se procede a realizar un análisis sobre la responsabilidad contractual, económica y/o administrativa que subyace de la extinción del Contrato de Puesta a Disposición. La jurisprudencia ha ido evolucionando en base a pronunciamientos sobre situaciones concretas y ha permitido clarificar las circunstancias para la determinación sobre la contratación fraudulenta. Importante es esta por cuanto el carácter de la responsabilidad que ha de soportar la empresa usuaria queda vinculado directamente con dicha apreciación. Declarándose la responsabilidad de carácter solidaria cuando concurra conforme a los arts. 43 ET y i6.3 LETT.

PALABRAS CLAVE: responsabilidad empresarial, cesión de trabajadores, extinción del contrato, empresa usuaria, ETT, empresa de trabajo temporal, Contrato de Puesta a Disposición.

ABSTRACT: After a brief review of employment historic evolution by means of Temporary Work Agencies and the regulatory framework on which this kind of labour relationships stand, we perform an analysis of contractual, financial and/or administrative responsibility underlying the termination of contract with the user undertaking. Jurisprudence has evolved on the basis of pronouncements on specific situations and has allowed clarifying the circumstances to determine fraudulent procurement. This is important since the nature of the liability which the client company has to bear is directly linked to that assessment. Responsibility for declaring solidarity character upon the occurrence pursuant to articles 43 ET and i6.3 LETT. 
KEYWORDS: corporate responsibility, cesion of employees, termination of contract, user undertaking, Temporary Work Agencies, Contract with the user undertaking.

\section{Introducción: evolución y causas del Contrato de Puesta a Disposición}

En la actualidad, las Empresas de Trabajo Temporal (ETT en adelante) ceden trabajadores a las empresas usuarias de forma temporal, también conocidos como trabajadores en misión, evitando a estas últimas la realización de contratos de trabajo. Esta situación es implementada desde mayo de 1994, cuando se habilitó legalmente este sistema de cesión temporal de trabajadores a través de las ETT' ${ }^{\mathrm{I}}$. Desde entonces y hasta la actualidad, dicha contratación se ha venido realizando a través del Contrato de Puesta a Disposición (CPD en adelante) realizado entre la empresa usuaria y la propia ETT. Pero no fue hasta el siguiente año, en I995, cuando se producen las primeras estadísticas en España de dichas contrataciones por mediación de las ETT ${ }^{2}$, así pues, según los datos del INE propuestos en el Gráfico I, sobre la evolución del número de CPD realizados durante el periodo I996-2013, observamos cómo se ha producido un gran incremento en la realización de los mismos, esto se ha debido a varios factores:

En primer lugar, a la necesidad de flexibilidad de las empresas para adaptarse a la temporalidad ${ }^{3}$ y a la estacionalidad ${ }^{4}$ del mercado de trabajo español, donde los ciclos de dicha estacionalidad se pueden observar en el Gráfico 2, sobre la evolución mensual del número de CPD en el periodo I996-2013

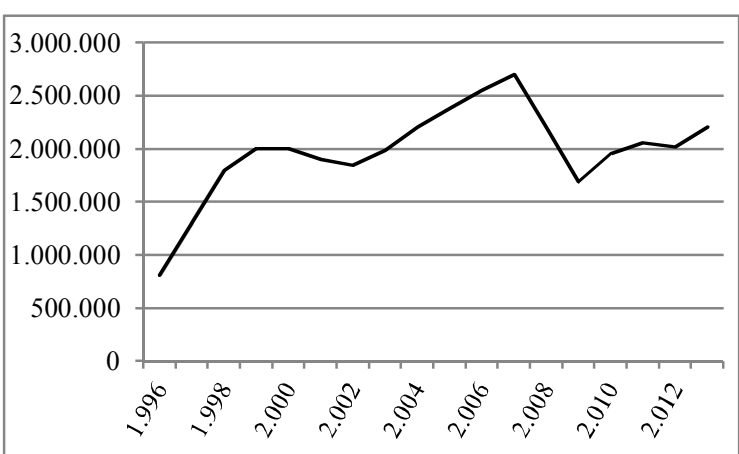

Gráfico I. Evolución anual de CPD (1996-2013)

Fuente: www.ine.es. Elaboración propia.

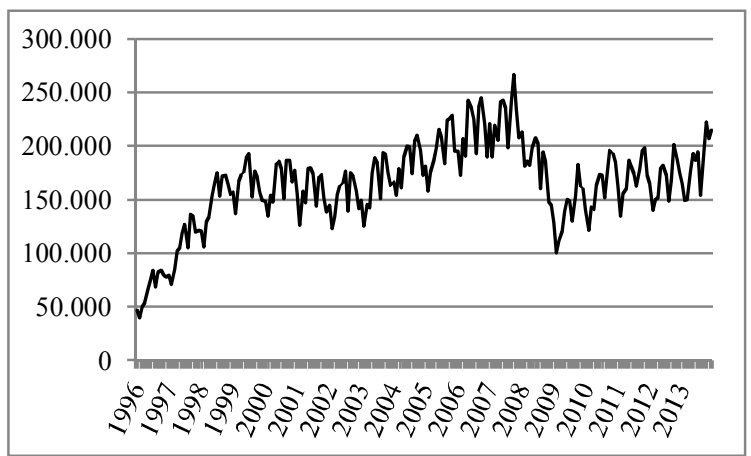

Gráfico 2. Evolución mensual de CPD (1996-2013)

Fuente: www.ine.es. Elaboración propia.

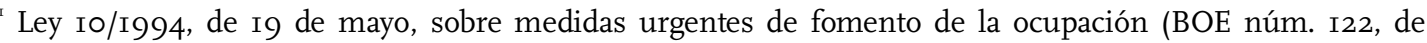
23/05/I994) Artículo 2.I «La contratación de trabajadores para cederlos temporalmente a otra empresa sólo podrá efectuarse a través de empresas de trabajo temporal debidamente autorizadas en los términos que legalmente se establezcan.»

Boletín de Estadísticas Laborales. Ministerio de Empleo y Seguridad Social (disponible en www.empleo.gob.es/estadisticas/bel/welcome.htm; fecha de consulta: 20/04/20I4).

${ }^{3}$ Elordi Dentici, A. (coord.), Trabajo, temporalidad y Empresas de Trabajo Temporal en España, Madrid, AGETT, 200I, págs. I29-I37, pone de manifiesto que ya, a partir de I987, puede tomarse la temporalidad como una de las principales características del mercado laboral español, momento en el que la tasa de temporalidad supera el $20 \%$.

${ }^{4}$ SEPE / Red EURES. Mercado de trabajo en España. Fecha: Mayo 20I3, donde cabe señalar el sector de la agricultura y el sector servicios, con las ramas del comercio, el turismo y la hostelería, como los más afectados por este fenómeno (disponible en www.sepe.es/contenido/empleo_formacion/eures/pdf/MT_Espana.pdf; fecha de consulta: 20/04/20I4). 
En segundo término, como resultado de las nuevas formas de organización empresarial y el fenómeno conocido en la literatura económica anglosajona como «outsourcing», o, lo que es lo mismo, la externalización del trabajo y su consecuente reducción de los costes fijos y el riesgo económico asumido por las empresas.

Ambas causas relacionadas han potenciado otras formas de trabajo diferentes de la relación convencional desarrollada por cuenta ajena ${ }^{6}$-como son la externalización, la subcontratación empresarial, el teletrabajo o la utilización del trabajo autónomo ${ }^{7}$ entre otros-, donde el CPD forma sólo una herramienta más a disposición de las empresas para la gestión de los empleados.

Asimismo, el denominado «outsourcing» explicaría por qué el sector industrial, sin tener una excesiva correspondencia con el fenómeno de la estacionalidad, pero sí con el de la temporalidad y la necesidad de flexibilizar la plantilla, tiene unas cifras de CPD utilizados tan significantes como muestra la Tabla I.

Debido a la magnitud y trascendencia social de esta práctica es por lo que se pretende analizar desde un punto de vista jurídico-laboral los diferentes tipos de responsabilidad derivada así como los sujetos implicados tras la extinción del Contrato de Puesta a Disposición.

\begin{tabular}{|c|c|c|c|c|c|c|c|c|c|c|}
\hline & 2004 & 2005 & 2006 & 2007 & 2008 & 2009 & 2010 & $20 I I$ & 2012 & 2013 \\
\hline Total & 2.209 .477 & 2.384 .045 & 2.557 .097 & 2.705 .043 & 2.207 .585 & I.691.013 & I. 957.564 & 2.062 .536 & I.717.906 & 2.209 .602 \\
\hline Agrario & I 27.832 & I30.308 & $\mathrm{I} 73.402$ & 208.385 & 202.I44 & 206.377 & 240.793 & 285.964 & 280.645 & 4II.794 \\
\hline Industrial & 733.292 & 767.283 & $8 \mathrm{I} 4.522$ & 810.756 & 612.090 & 427.060 & 537.254 & 560.333 & $443.54^{2}$ & 600.752 \\
\hline Servicios & I. 300.923 & I. 439.427 & I. 523.553 & I.63I.34I & I.36I.IO8 & I.04I.078 & I.I56.5I7 & I.I94.33I & 980.450 & I.I80.104 \\
\hline Otros & 47.430 & 47.027 & 45.620 & $54.56 \mathrm{I}$ & 32.243 & I6.498 & 23.000 & 21.908 & 13.269 & $16.95^{2}$ \\
\hline
\end{tabular}

Tabla I. Utilización del CPD por sector y año (2004-2013) Fuente: www.ine.es. Elaboración propia.

\footnotetext{
${ }^{5}$ SChneider, B., Outsourcing: La herramienta de gestión que revoluciona el mundo de los negocios, Bogotá, Editorial Norma, 2004.

${ }^{6}$ Moreno Vida, M. N., El trabajo en régimen de Empresas de Trabajo Temporal. Estudio del ordenamiento interno y comunitario, Granada, Comares, 2005, págs. 2-4.

${ }^{7}$ La Ley 20/2007, de II de julio, del Estatuto del trabajo autónomo (BOE núm. I66, de I2/07/2007), recoge en su Capítulo III el Régimen profesional del trabajador económicamente dependiente conceptualizando esta figura como aquella actividad económica o profesional «de forma habitual, personal, directa y predominante para una persona física o jurídica, denominada cliente, del que dependen económicamente» [art. II.I LETA]. Además, el 4 de marzo de 2009 se publicó el Real Decreto I97/2009, de 23 de febrero, por el que se desarrolla el Estatuto del Trabajo Autónomo en materia de contrato del trabajador autónomo económicamente dependiente y su registro, desarrollando el Contrato de trabajo de los trabajadores autónomos económicamente dependientes (BOE núm. 54, de 04/03/2009).
} 


\section{Marco legal de la cesión de trabajadores}

El artículo 43.I del Estatuto de los Trabajadores ${ }^{8}$ es tajante al establecer que la cesión de trabajadores sólo puede efectuarse a través de las ETT, por lo que resulta necesario observar la regulación legal de las mismas para poder establecer el marco normativo de la cesión legal ${ }^{9}$ de trabajadores.

Dentro del ámbito de aplicación y bajo la jerarquía normativa nos encontramos con legislación emanada de distintos organismos internacionales como son la Organización Internacional del Trabajo o la Comisión Europea, por lo que conviene diferenciar entre esta regulación establecida en el Derecho supranacional y la propia establecida en el Derecho español.

\section{II.I. Derecho supranacional}

Tanto desde el ámbito internacional, como desde el ámbito comunitario, existe normativa con fuerza vinculante en España, bien por ratificación de los tratados internacionales, o bien por las directivas de aplicación directa de la propia Unión Europea. Así pues, cabe destacar en el ámbito internacional el Convenio número I8I de la OIT (Ci8I en adelante $)^{\text {to }}$, el cual establece las obligaciones administrativas y de garantía de los derechos de los trabajadores así como de condiciones de trabajo con respecto a la legislación nacional ${ }^{\text {II y } 12}$.

En el ámbito europeo, el ejercicio de las ETT data desde la década de los 80 del siglo pasado o incluso algunos años antes ${ }^{13}$, si bien, la primera armonización normativa en la Unión Europea no se produce hasta el año 2008 con la Directiva 2008/I04/CE ${ }^{14}$ cuyo proyecto de realización comenzó en $1983^{15}$, lo cual, pone de manifiesto la dificultad de armonizar legislación en un tema social tan relevante al coexistir una multitud de intereses, tanto políticos, como económicos y sociales.

\footnotetext{
${ }^{8}$ Aprobado por el RDL I/I995, de 24 de marzo, por el que se aprueba el texto refundido de la Ley del Estatuto de los Trabajadores (BOE núm. 75, de 29/03/1995).

${ }^{9}$ Importante remisión al término «legal» por cuanto la cesión ilegal de trabajadores está tipificada como delito en el artículo 3I2.I de la Ley Orgánica Io/I995, de 23 de noviembre, del Código Penal, (BOE Núm. 28I, de I7/OI/2OI3) y «con las penas de prisión de dos a cinco años y multa de seis a doce meses.»

${ }^{10}$ Convenio número I8I, de la OIT, sobre las agencias de empleo privadas, de I9 de junio de i997. Ratificado por España mediante el Instrumento de Ratificación del Convenio número i8I de la Organización Internacional del Trabajo sobre las Agencias de Empleo Privadas, hecho en Ginebra el iو de junio de I997.

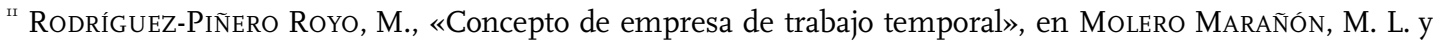
VAldÉs DAL-RÉ, F. (dirs.), Comentarios a la Ley de Empresas de Trabajo Temporal, Madrid, La Ley, 2009, págs. 5354 .

${ }^{\text {I2 }}$ El Ci8I establece en su artículo 5 el derecho a la no discriminación y de igualdad de oportunidades y en su artículo II, con respecto a la legislación nacional, encomienda a los países que lo ratifiquen el establecimiento de garantías sobre el derecho a la libertad sindical y de negociación colectiva; salarios mínimos; tiempo de trabajo; prestaciones de seguridad social; indemnizaciones por accidentes de trabajo e insolvencia empresarial; protección por maternidad y acceso a la formación entre otros.

${ }^{13}$ Solas Picó, M. T., «Flexibilidad del mercado de trabajo y creación de empleo», Acciones e investigaciones sociales, O, I99I, pág. III, pone de manifiesto que en Bélgica «se reguló la actividad de las empresas de trabajo temporal y la contratación de duración determinada» a través de la Ley de 28 de julio de ${ }_{1976} 6$.

${ }^{14}$ Directiva 2008/104/CE del Parlamento Europeo y del Consejo, de I9 de noviembre de 2008, relativa al trabajo a través de empresas de trabajo temporal, (DOUEL núm. 327, de 05/12/2008).

${ }^{15}$ RodrígueZ-PiÑERo RoYo, M., «Concepto...», cit., pág. 53.
} 
Los legisladores de dicha directiva quisieron ponderar por un lado, los intereses empresariales, como la eliminación de las limitaciones administrativas, exceptuando las justificadas al amparo del interés general, y por el otro, los intereses de los trabajadores cedidos, como el de consagrar el principio de igualdad de trato entre trabajadores de la empresa usuaria y los cedidos a la misma ${ }^{\mathrm{i} 6}$. Con el principio de igualdad consagrado ${ }^{\mathrm{I} 7}$ [arts. 5.I y 6.I de la Directiva] se clarifica el marco normativo que ha de aplicarse a los trabajadores en misión, salvo las restricciones que prevalezcan en cada país, ya que se aplicarán las mismas condiciones laborales que a los trabajadores contratados por la empresa usuaria ${ }^{\mathrm{I}}$.

\section{II.2. Derecho español}

El Decreto-Ley de $1952^{\text {19 }}$ separó la figura de subcontratación de trabajadores bajo la dirección de un empresario para la prestación de servicios con carácter temporal a otra empresa, de la figura de la cesión de trabajadores como actividad empresarial, quedando esta segunda prohibida taxativamente con sus respectivas responsabilidades y sanciones según el artículo segundo de dicho Decreto-Ley ${ }^{20}$.

En el mismo sentido, el anterior Estatuto de los Trabajadores de $1980^{2 \mathrm{I}}$ siguió manteniendo expresamente en su artículo 43 dicha prohibición de cesión de trabajadores; así como un régimen sancionador y de responsabilidad empresarial. Prohibición vigente hasta 1993 cuando, mediante distintos instrumentos legislativos ${ }^{22}$, se modificó radicalmente el régimen de la cesión de trabajadores, quedando legalizado y regulado con la vigente LETT $^{23}$ y el actual ET ${ }^{24}$.

${ }^{16}$ Gala DurÁn, C., «La Directiva sobre empresas de trabajo temporal y su impacto en España.», Temas laborales: Revista andaluza de trabajo y bienestar social, I02/2009, págs. I6 y ss.

${ }^{17}$ Para un estudio más a fondo de la extensión del principio de igualdad de trato consultar López AHUMADA, J. E. «Reflexiones sobre el aumento de la protección de los trabajadores cedidos por las empresas de trabajo temporal: garantías y ausencias desde la óptica de la flexiseguridad», Temas laborales: Revista andaluza de trabajo Y bienestar social, I16/2012, págs. 95 y ss.

${ }^{18}$ Rodríguez-PiÑERo Royo, M., «Concepto...», cit., págs. 55 y ss. Señala que dentro del tejido normativo europeo, entre otras, destaca la importancia de otras dos directivas: la Directiva I996/7I/CE sobre el desplazamiento de trabajadores efectuado en el marco de una prestación de servicios (trasnacional) y la Directiva I99I/383/CE para la promoción de la mejora de la seguridad y salud en el trabajo temporal o mediante ETT.

${ }^{19}$ Decreto-Ley, de I5 de febrero de I952, por el que se establecen responsabilidades de carácter civil y penal por incumplimiento de leyes laborales y de previsión social, (BOE núm. 6I, de or/o3/1952).

${ }^{20}$ Alonso García, M., «Contrato de trabajo, subcontrata y cesión de mano de obra», Revista de Política Social, enero-marzo, 45/1960, págs. 50 y ss., donde destaca responsabilidades de tipo civil, administrativo y penal.

${ }^{21}$ Ley 8/1980, de ıo de marzo, del Estatuto de los Trabajadores, (BOE núm. 64, dei4/o3/ı980). Artículo cuarenta y tres. Cesión de trabajadores. «Uno. Se prohíbe el reclutamiento y la contratación de trabajadores para prestarlos o cederlos temporalmente a un empresario, cualquiera que sean los títulos de dicho tráfico de mano de obra, así como la utilización de los servicios de dichos trabajadores, sin incorporarlos al personal de la empresa en que trabajan.»

${ }^{22}$ Destacar entre otros el Real Decreto-ley I8/1993, de 3 de diciembre, de Medidas Urgentes de Fomento de la Ocupación, (BOE núm 292, de 07/I2/1993) y la Ley Io/ı994, que derogaron el art. 43 del anterior ET I980 que prohibía la cesión de trabajadores.

${ }^{23}$ Ley I4/I994, de I de junio, por la que se regulan las Empresas de Trabajo Temporal, (BOE núm. I3I, de 02/06/I994). Artículo I Concepto. «Se denomina empresa de trabajo temporal aquélla cuya actividad fundamental consiste en poner a disposición de otra empresa usuaria, con carácter temporal, trabajadores por ella contratados. La contratación de trabajadores para cederlos temporalmente a otra empresa sólo podrá efectuarse a través de empresas de trabajo temporal debidamente autorizadas en los términos previstos en esta Ley.» 
Con el marco legislativo actual, ya adaptado a la Directiva 2008/104/CE ${ }^{25}$, se distinguen hasta tres figuras organizativas diferentes que median entre empresarios y trabajadores, como son las agencias de colocación, las empresas de selección y las propias Empresas de Trabajo Temporal. Correspondiendo exclusivamente a estas últimas la posibilidad de ceder trabajadores legalmente a las empresas usuarias ${ }^{26}$.

Si bien es cierto, no es esta su única función, puesto que también realizan frecuentemente la función de selección de personal y, además, pueden actuar como agencias de colocación, siempre y cuando cumplan los requisitos establecidos para ello ${ }^{27}$.

En todo caso, es requisito imprescindible para que las ETT puedan desarrollar su actividad que estén debidamente autorizadas ${ }^{28}$. Cuestión esta problemática por cuanto las autorizaciones se conceden en distintos niveles de ámbito geográfico como son el provincial, el autonómico o el estatal y, además, se distingue entre el lugar de desempeño de la actividad laboral y el ámbito geográfico de la realización del propio $\mathrm{CPD}^{29}$. Cuya solución llegó con el actual artículo 5 LETT $^{30}$ al permitir el desempeño de la actividad laboral en un lugar para el que la ETT carece de autorización administrativa, siempre y cuando el ámbito de realización del CPD sea dentro del ámbito de dicha autorización, en cuyo caso tendrá que notificar con carácter previo a la autoridad laboral competente en el territorio de la prestación de servicios [art. 5.3 LETT].

\section{II.3. El Contrato de Puesta a Disposición: Límites y exclusiones}

El Contrato de Puesta a Disposición es un contrato de naturaleza privada ${ }^{31}$ cuyo objeto, dentro del marco jurídico-laboral, es «la cesión del trabajador (por parte de la ETT) para prestar servicios en la empresa usuaria, a cuyo poder de dirección quedará sometido» [art. 6.I LETT] y que deberá formalizarse por escrito ${ }^{32}$, así como respetar, en todo caso, los límites

${ }^{24}$ Real Decreto Legislativo I/I995, de 24 de marzo, por el que se aprueba el texto refundido de la Ley del Estatuto de los Trabajadores (BOE núm. 75, de 29/03/1995) Artículo 43 Cesión de trabajadores. «I. La contratación de trabajadores para cederlos temporalmente a otra empresa sólo podrá efectuarse a través de empresas de trabajo temporal debidamente autorizadas en los términos que legalmente se establezcan.»

${ }^{25}$ Adaptado mediante el artículo I7 de la Ley 35/20IO, de I7 de septiembre, de medidas urgentes para la reforma del mercado de trabajo (BOE núm. 227, de I8/09/20II).

${ }^{26}$ Montoya Melgar, A., Derecho del Trabajo, trigésima cuarta edición, Madrid, Tecnos, 2013, págs. 580 a 58I.

${ }^{27}$ LETT. Artículo I Concepto. «(...) Las empresas de trabajo temporal podrán, además, actuar como agencias de colocación cuando cumplan los requisitos establecidos en la Ley 56/2003, de i6 de diciembre, de Empleo, y su normativa de desarrollo.»

${ }^{28}$ Como ponen de manifiesto los arts. 2.I LMUFO; I LETT y 43.I ET, entre otros.

${ }^{29}$ Problemática analizada doctrinal y legalmente en PÉREZ Guerrero, M. L. y RODRIGUEZ-PiÑERo RoYo, M., «El artículo 43 del Estatuto de los Trabajadores: Empresas de trabajo temporal y cesión de trabajadores», Revista del Ministerio de Trabajo y Asuntos Sociales, 58/2005, págs. I85 y ss.

${ }^{30}$ Modificado por el Artículo único Cuatro de la Ley 29/1999, de I6 de julio, de Modificación de la Ley I4/I994, de I de junio, por la que se regulan las Empresas de Trabajo Temporal (BOE núm. I70, de I7/07/1999).

${ }^{31}$ Como se puede ver en la Disp. Ad. Primera LETT que establece que «en todo lo no previsto en la presente Ley se aplicará la legislación laboral y de Seguridad Social (...) y la legislación civil y mercantil a las relaciones entre la empresa de trabajo temporal y la empresa usuaria.»

${ }^{32}$ Según Moreno Vida, M. N., El trabajo..., cit., pág. 42: «Como garantía de seguridad jurídica y de control público de su contenido.» 
del régimen general de la contratación temporal como si esta la realizara la empresa usuaria ${ }^{33}$.

\section{a) Límites}

El artículo 6.2 LETT remite explícitamente a las condiciones y requisitos sobre los contratos de trabajo para la realización de una obra o servicio determinado; eventual por circunstancias de la producción, de interinidad y de los contratos en prácticas o para la formación y el aprendizaje. Contratos para los que los límites difieren unos de otros del siguiente modo:

- Los contratos para la realización de una obra o servicio determinado, de duración incierta, «no podrán tener una duración superior a tres años ampliable hasta doce meses más por convenio colectivo de ámbito sectorial.» [art. I5.I a) ET]

- Los contratos eventuales por circunstancias de la producción «podrán tener una duración máxima de seis meses, dentro de un período de doce meses.» Ampliables por convenio sectorial hasta una duración máxima de doce meses en un período máximo de dieciocho, aunque tampoco podrán superar las tres cuartas partes del período de referencia quedando incluidas las prórrogas realizadas [art. I5.I b) ET].

- Los contratos de interinidad, también de duración incierta, no tienen una fecha de finalización conocida si no que será el fin de la causa que lo motivó la que opere como fecha de finalización del contrato [art. I5.I c) ET].

- Los contratos de trabajo en prácticas no podrán ser inferiores «a seis meses ni exceder de dos años» [art. II.I b) ET], si bien, tampoco podrán exceder los dos años en la misma o distintas empresas en virtud de la misma titulación o certificado de profesionalidad, ni en la misma empresa, para el mismo puesto de trabajo, aunque se trate de distinto título o certificado de profesionalidad [art. II.I c) ET].

- Los contratos para la formación y el aprendizaje, en régimen de alternancia de actividad laboral retribuida en una empresa con una actividad formativa, se podrán celebrar con trabajadores de entre dieciséis y veinticuatro años ${ }^{34}$, con una «duración mínima del contrato de un año y la máxima de tres», aunque mediante convenio colectivo se podrá acordar la duración mínima de hasta seis meses respetando el máximo de tres años [art. II.2 b) ET].

b) Exclusiones

${ }^{33}$ STS, de 22 de octubre de I999, Rcud.I77/I999, señala que «el contrato de puesta a disposición no puede ser una vía para alterar el régimen general de la contratación temporal, sino únicamente un instrumento para trasladar la temporalidad del ámbito de contratación de la empresa usuaria a la empresa de trabajo temporal» $\left(\mathrm{FD} 3^{\circ}\right)$

${ }^{34}$ Límite de edad suspendido temporalmente ya que se podrán realizar este tipo de contratos con trabajadores menores de 30 años según la Disposición transitoria novena de la Ley 3/20I2, de 6 de julio, de medidas urgentes para la reforma del mercado laboral (BOE núm. I62, de 07/07/20I2), en cuanto la tasa de desempleo no disminuya por debajo del I5 por ciento. 
Aunque la LETT apunta hacia las condiciones generales de contratación ${ }^{35}$, también hay que tener en cuenta que la misma ha reservado cuatro supuestos de exclusión [art. 8 LETT] para la realización del CPD como son:

- La sustitución de trabajadores en huelga en la empresa usuaria [art. 8.a) LETT]. Expresado en la misma línea que el artículo 6.5 RDLRT $^{36}$ que establece que «en tanto dure la huelga, el empresario no podrá sustituir a los huelguistas por trabajadores que no estuviesen vinculados a la empresa» encontrándose así, dentro de la protección y del contenido esencial de la Libertad Sindical y su ejercicio [arts. 28.I y .2 CE y 2.2 d) LOLS ${ }^{37}$ ].

- La contratación en determinados puestos u ocupaciones especialmente peligrosos para la seguridad y salud en el trabajo ${ }^{3^{8}}$ [art. 8.b) LETT]. Completado con la Disposición Adicional Segunda de la misma ley al remitir a unos supuestos concretos y dejar abierta la vía de la negociación colectiva recogida en el artículo 83 del Estatuto de los Trabajadores para definir la relación concreta de puestos de trabajo que no podrán ser objeto de cesión de trabajadores.

- Cubrir los puestos amortizados en los últimos doce meses por despido improcedente, reconocido tanto por los tribunales como por el empresario en la resolución contractual $^{39}$, o en las causas establecidas por los artículos 50, 5 I y $5^{2}$. c) $\mathrm{ET}^{40}$ salvo los supuestos de fuerza mayor.

- La cesión de trabajadores a otras ETT para evitar la sub-cesión de trabajadores ${ }^{4 \mathrm{t}} \mathrm{y}$ una continua encadenación de contratos ${ }^{42}$, así como mantener delimitado el régimen de responsabilidad en la relación triangular entre trabajador, empresa usuaria y $\mathrm{ETT}^{43}$.

${ }^{35}$ VALDÉs DAL-RÉ, F., «Contrato de Puesta a Disposición: Objetivo, supuestos de utilización, forma y duración», en Molero Marañón, M. L. y Valdés Dal-RÉ, F. (dirs.), Comentarios a la Ley de Empresas de Trabajo Temporal, cit., págs. 236 y ss.

${ }^{36}$ Real Decreto-ley I7/I977, de 4 de marzo, sobre relaciones de trabajo. (BOE núm. 58, de 09/03/I977) vigente bajo los criterios establecidos por el Tribunal Constitucional en la STC II/I98I, de 8 de abril de I98I, y posteriores.

${ }^{37}$ Ley Orgánica II/1985, de 2 de agosto, de Libertad Sindical (BOE núm. I89, de 08/08/1985).

${ }^{38}$ LÓPEZ Balaguer, M., «Supuestos excluidos de utilización del Contrato de Puesta a Disposición» en Molero Marañón, M. L. y Valdés Dal-Ré, F. (dirs.), Comentarios a la ley de Empresas de Trabajo Temporal, cit., pág. 253. Señala, en todo caso, que el alcance de dicho precepto no es sino una remisión al artículo 8 del Real Decreto 216/1999, de 5 de febrero, sobre disposiciones mínimas de seguridad y salud en el trabajo en el ámbito de las empresas de trabajo temporal.

39 Ibíd., págs. 259 y ss. Para proteger el empleo propio y estable frente al empleo temporal y precario, evitando así, prácticas abusivas y fraudulentas sin llegar a entenderse como amortización de puestos de trabajo cuando en el momento de la extinción contractual por despido improcedente hubiera el mismo o menor número de trabajadores desempeñando el mismo puesto de trabajo que en el momento en que se realizaran las incorporaciones mediante el CPD, independientemente de la temporalidad o parcialidad de dichos trabajadores. [En sentencia citada por la autora STSJ de La Rioja núm. 533/2000, de 29 septiembre, de la Sala de lo Contencioso-Administrativo $\left(\mathrm{FD} 3^{\circ}\right)$ ]

$4^{\circ}$ Entre dichas causas recogidas en el Estatuto de los Trabajadores se encuentran los incumplimientos graves o la modificación sustancial de las condiciones del contrato [art. 50 ET]; el despido colectivo [art. 5I ET] o en caso de extinción del contrato individual cuando concurran las causas económicas, técnicas, organizativas o de producción. [art. 52. c) ET]

${ }^{4 \mathrm{r}}$ Tipificado como infracción muy grave en el artículo I8.3 e) LISOS «Ceder trabajadores con contrato temporal a otra empresa de trabajo temporal o a otras empresas para su posterior cesión a terceros.»

\footnotetext{
${ }^{42}$ Moreno Vida, M. N., El trabajo..., cit., pág. 46.

${ }^{43}$ LóPeZ BALAGUeR, M., «Supuestos...», cit., págs. 264 y ss.
} 


\section{Responsabilidad tras la extinción del Contrato de Puesta a Disposición}

Sin perjuicio de la responsabilidad resultante tras una utilización inadecuada del Contrato de Puesta a Disposición en lo referente al objeto del mismo o respecto de sus exclusiones recogidas en el artículo 8 LEET, ya estudiadas anteriormente, se pretende analizar la responsabilidad derivada tras la extinción del CPD en cuanto a los supuestos que la generan y los tipos de esta que se producen, centrándonos tanto en la responsabilidad económica como en la contractual, analizando las posibilidades de interpretación y aplicación.

\section{III.I. Supuestos conflictivos}

Al margen de todas las causas recogidas en el artículo 49 y ss. del Estatuto de los Trabajadores, respecto de la extinción del contrato de trabajo, existen cinco supuestos conflictivos dentro de esta relación triangular -como son: la extinción «ante tempus» del contrato de trabajo; la prestación de servicios en la empresa usuaria tras la extinción del contrato; la extinción tras la contratación sucesiva del trabajo mediante ETT; la limitación temporal recogida en el artículo I5.5 ET y la prohibición de contratación del trabajador por la empresa usuaria- que van a ser objeto de estudio para esclarecer y dirimir la situación en que éstos pueden producirse conforme a derecho.

III.2. Extinción «ante tempus» del contrato de trabajo

Encontramos dos vertientes diferentes ante el supuesto de extinción del contrato «ante tempus» en función de si la fecha de finalización del mismo es, o no, concreta en el tiempo ${ }^{44}$. Así pues, por ser los más utilizados, de entre los contratos en que su extinción no está determinada en el tiempo, pero sí en su objeto, destaca el realizado por obra o servicio determinado y de entre los que su finalización está definida en una fecha exacta en el momento de su realización, destaca el eventual por circunstancias de la producción.

En ambos casos, además, hay que atender a las condiciones generales de la contratación [art. 6.2 LETT] donde encontramos las particularidades de los distintos tipos de contrato, sin perjuicio de la superación del período de prueba por parte del trabajador, pues opera como una de las causas de extinción al amparo del artículo I4.2 $\mathrm{ET}^{45}$.

${ }^{44}$ Sempere Navarro, A. y Cardenal Carro, M., «La necesaria sujeción del contrato eventual a un término final y la STS de 4 de febrero de I999», Revista Doctrinal Aranzadi Social, 5, I999, págs. II5-I26. Tras un análisis y crítica de dicha sentencia, señala que la finalización del contrato de trabajo puede estar supeditada a una fecha exacta o a la ocurrencia de un hecho que indicaría dicho fin destacando de entre éstos último la realización de una obra o servicio o el fin de la obligación de reserva de puesto de los contratos de interinidad, pero nunca la extinción voluntaria por parte de la empresa usuaria (ni del CPD ni del contrato de trabajo), ni el fin del motivo que propició el contrato eventual por circunstancias de la producción.

${ }^{45}$ El artículo I4 ET, además del régimen jurídico subsidiario sin perjuicio de lo dispuesto en los convenios colectivos, la causa extintora del contrato de trabajo de forma unilateral por cualquiera de las partes al recoger en su punto segundo que «Durante el período de prueba, el trabajador tendrá los derechos y obligaciones correspondientes al puesto de trabajo que desempeñe como si fuera de plantilla, excepto los derivados de la resolución de la relación laboral, que podrá producirse a instancia de cualquiera de las partes durante su transcurso.» En todo caso, para un estudio más a fondo sobre el régimen jurídico del período de prueba consultar Iranzo Fernández-Valladares, M., «Artículo i4. Período de prueba» en Del Rey Guanter, S. (dir.), Estatuto de los Trabajadores comentado y con jurisprudencia, $3^{\text {a }}$ edición, Madrid, La Ley, 2013, págs. 357-367. 
a) Contrato para la realización de una obra o servicio determinado

Sin ser necesario que finalice totalmente la obra o servicio se admite la posibilidad de realizar una extinción gradual ${ }^{46}$ de los contratos de trabajo bajo el criterio y subjetividad de la propia empresa ${ }^{47}$.

Aun así, para este tipo de contratos se exige la realización de una actividad con «autonomía y sustantividad propia» [art. I5.I a) ET], o lo que es lo mismo, que dicha actividad identificada posea un principio y un fin definido objetivamente ${ }^{48}$. Además, al vincularse la duración del contrato a la finalización de la obra o servicio no está permitida la realización de prórrogas a dichos contratos ${ }^{49}$ pero sí se contempla la posibilidad de encadenar distintos contratos por obra o servicio siempre que el objeto del contrato de trabajo mantenga la sustantividad propia referida anteriormente ${ }^{50}$.

b) Contrato eventual por circunstancias de la producción

Igual que la cuestión anterior, necesitó de pronunciamientos jurisprudenciales, como la STS, de 4 de febrero de I999, Rcud. 2022/1998, para aclarar que se debe fijar una fecha exacta de finalización del contrato de trabajo (FD $3^{\circ}$ ) y, si bien se puede prorrogar, no son válidas las clausulas que vinculan la extinción de dicho contrato a la pervivencia de la relación privada establecida entre la empresa usuaria y la $\operatorname{ETT}^{51}\left(\mathrm{FD} 4^{\circ}\right)$, exigiéndose así, a la empresa, el establecimiento de una fecha cierta de finalización para evitar la arbitrariedad y la precarización, pues se presume que la empresa usuaria dispone de la información necesaria suficiente para organizar la producción a corto plazo, al menos, por el tiempo suficiente que dure la contratación (FD $3^{\circ}$ ).

c) Contratos de interinidad

${ }^{46}$ Sala Franco, T., Pérez Infante, J. I. y López Terrada, E., Las modalidades de la contratación laboral, Valencia, Tirant lo Blanch, 2009, pág. 83. Y la reciente STS, de 28 de abril de 20I4, Rcud. 900/20I3, (FD 2) donde argumenta que la propia sala ya había entendido que «la finalización paulatina (de la obra) era prueba suficiente para justificar la extinción contractual.»

${ }^{47}$ Ahora bien, la propia STS, de 28 de abril de 20I4, Rcud. 900/20I3, (FD 2 ${ }^{\circ}$ ) reconoce la posibilidad de la empresa de incurrir en fraude cuando «extingue contratos con unos mientras contrata otros nuevos; o que extingue contratos de categorías que sigue necesitando en lugar de las que ya no son necesarias.»

${ }^{48}$ STS, de 28 de febrero de I996, Rcud. 263I/I995 citada por Sala Franco, T., PÉRez Infante, J. I. y López TERRADA, E. Las modalidades..., cit., pág. 83.

${ }^{49}$ Sala Franco, T., Pérez Infante, J. I. y López Terrada, E., Las modalidades..., cit., pág. 8I.

${ }^{50}$ Ibíd., pág. 78.

${ }_{5}$ Aunque el art. IO.I LETT sólo da dos opciones respecto de la duración de la relación laboral, bien sea indefinida con la ETT o bien esté vinculada a la duración del contrato de puesta a disposición, se pretende con ello evitar que la ruptura, de forma unilateral por parte de la empresa usuaria, de la relación jurídica con la ETT sea causa vinculante para la extinción del contrato de trabajo. Tomando así la base del artículo i256 CC que establece que «la validez y el cumplimiento de los contratos no pueden dejarse al arbitrio de uno de los contratantes». 
Son aquellos contratos de trabajo celebrados para sustituir a un trabajador con derecho a reserva de puesto de trabajo [art. I5.I c) ET] $]^{52}$, o para cubrir temporalmente un puesto de trabajo durante el proceso de selección o promoción [art. 4.I RD 2720/1998 $8^{53}$ ], y con una duración máxima que «será la del tiempo que dure la ausencia del trabajador sustituido con derecho a la reserva del puesto de trabajo», o bien, «la del tiempo que dure el proceso de selección o promoción para la cobertura definitiva del puesto, sin que pueda ser superior a tres meses» [art. 4.2 RD 2720/1998 y STS, de I9 de septiembre de 2000, Rcud. 3904/1999, $\left.\left(\mathrm{FD}^{\circ}{ }^{\circ}\right)\right]$.

Al igual que para el contrato para la realización de una obra o servicio determinado, en esta modalidad tampoco cabe posibilidad alguna de prorrogar el mismo, pero sí la de encadenar diversos contratos siempre que exista una nueva causa ajustada al objeto de esta modalidad contractual.

También es importante observar como la STS, de 4 de febrero de I999, Rcud. 2022/1998, desestimó el argumento basado en la existencia de una clausula convencional que contenía la extinción anticipada por causas no imputables a la ETT (FD $5^{\circ}$ ) remitiendo al «mecanismo extintivo conforme a los artículos 5I ó 52 c) del Estatuto de los Trabajadores ${ }^{54} \gg\left(\mathrm{FD}_{2}^{\circ}\right)$.

Así pues, la decisión de extinguir el contrato de trabajo «ante tempus» que no esté amparada por causas económicas, técnicas, organizativas o de producción ${ }^{55}$ del procedimiento de despido colectivo [art. 5I.I c) ET]; por cualesquiera de las causas de extinción objetivas [art. $52 \mathrm{ET}$ ]; basada en un incumplimiento grave y culpable del trabajador [art. 54 ET] o por la no superación del período de prueba [art. I4 ET] supondrá que dicha extinción no se ajuste a derecho declarándose improcedente o nula en caso de impugnación ante los tribunales de la Jurisdicción Social, con las consecuencias que de ello se deriven.

\section{III.I.I. Prestación de servicios en la empresa usuaria tras la extinción}

Aunque el artículo 7.2 LETT establezca que «si a la finalización del plazo de puesta a disposición el trabajador continuara prestando servicios en la empresa usuaria, se le considerará vinculado a la misma por un contrato indefinido», la realidad jurídica no parece tan clara, puesto que es necesario matizar esta situación con el régimen general de la contratación [art. 6.2 LETT] y con la propia jurisprudencia.

La STS, de 22 de octubre de I999, Rcud. I77/I999, suaviza la contundencia con la que el citado precepto vincula de forma indefinida al trabajador cedido con la empresa usuaria, donde coexisten un contrato de puesta a disposición y otro contrato de trabajo

${ }^{52}$ Sala Franco, T., Pérez Infante, J. I. y López Terrada, E., Las modalidades..., cit., págs. 98 y 99. Señala que tienen cabida situaciones de naturaleza diversa al remitirse a los supuestos de los artículos 37.3; 46.3; 46.6 y cualquiera de las establecidas en el 45 ET. Además de la recogida en la Disp. Transitoria sexta de la Ley 45/2002, de I2 de diciembre.

${ }^{53}$ Real Decreto 2720/1998, de i8 de diciembre, por el que se desarrolla el artículo I5 del Estatuto de los Trabajadores en materia de contratos de duración determinada (BOE núm. 7, de o8/oI/I999).

${ }^{54}$ Dichos artículos hacen referencia a los procedimientos para la extinción de contrato por causas económicas, técnicas, organizativas o de producción, tanto de forma colectiva, como de forma individual.

${ }^{55}$ Desarrolladas por el Reglamento de los procedimientos de despido colectivo y de suspensión de contratos y reducción de jornada [art. I y ss. RD I483/20I2, de 29 de octubre]. 
eventual por circunstancias de la producción entre la ETT, la empresa usuaria y el propio trabajador, que no abarca la duración máxima permitida, entendiéndose prorrogado tácitamente hasta dicho límite por la continuación en la prestación de servicios tras la extinción contractual por expiración del tiempo convenido (FD $3^{\circ}$ ), en aplicación del artículo 8.2 del RD 2546/1994, ya derogado ${ }^{56}$, que se expresaba en los mismos términos que el actual artículo 49.I c) párrafo tercero ET al establecer este último que «expirada dicha duración máxima o realizada la obra o servicio objeto del contrato, si no hubiera denuncia y se continuara en la prestación laboral, el contrato se considerará prorrogado tácitamente por tiempo indefinido, salvo prueba en contrario que acredite la naturaleza temporal de la prestación.»

Siendo esta naturaleza temporal un concepto jurídico indeterminado de compleja interpretación al quedar vinculada, en primer lugar, por las fórmulas de «la autonomía y sustantividad propia» [art. I5.I a) ET] en el caso de los contratos de obra o servicio determinado o por las «circunstancias del mercado, acumulación de tareas o exceso de pedidos (...) aun tratándose de la actividad normal de la empresa» [art. I5.I b) ET] para los contratos eventuales por circunstancias de la producción; en segundo término, por las situaciones singulares y la negociación colectiva [art. I5.I a) y b) ET] y, por último, por la interpretación jurisprudencial y las reformas legales acaecidas ${ }^{57}$.

\section{III.I.2. Extinción tras la contratación sucesiva del trabajo mediante ETT}

Distinto del caso anterior al entenderse que la relación laboral ha sido continuada al amparo de uno o varios contratos de trabajo expresos y no prorrogada tácitamente, este supuesto es especialmente problemático por cuanto se pretende enmascarar un único vínculo contractual con sucesivos $\mathrm{CPD}^{58}$ y han de tomarse en consideración a la hora de dilucidar los derechos y obligaciones de cada una de las partes los siguientes elementos: la responsabilidad de la empresa usuaria; el cómputo de la antigüedad y la limitación recogida en el artículo I5.5 del Estatuto de los Trabajadores ${ }^{59}$.

Cabe aclarar que, en todo caso, la sucesión de contratos no siempre representa un intento fraudulento de eludir las disposiciones legales, pues puede darse la posibilidad «de que concurra la causa objetiva que justifica la temporalidad pactada» ${ }^{60}$, ya que, como hemos señalado anteriormente, cabe la posibilidad de encadenar legalmente sucesivos contratos de obra o servicio determinado, eventuales por circunstancias de la producción, así como varios contratos de interinidad, entre otros, siempre y cuando concurran las causas legales establecidas para los mismos.

${ }_{56}^{6}$ Real Decreto 2546/1994, de 29 de diciembre, por el que se desarrolla el artículo I5 del Estatuto de los Trabajadores en materia de Contratación (BOE núm. 22, de 26/0I/I995) derogado por la Disposición derogatoria única del Real Decreto 2720/I998, de I8 de diciembre.

${ }^{57}$ GARCía QuiÑones, J. C., «Contratos temporales estructurales, contrato a tiempo parcial y contrato de relevo», en AA.VV, Contratación temporal, empresas de trabajo temporal y subcontratación en la negociación colectiva (colección: Informes y estudios. Serie Relaciones Laborales, 94/20I0), Madrid, Ministerio de Trabajo e Inmigración, 2010, págs. 47-48 y 97-99.

${ }^{58}$ Entendido así por la STSJ de País Vasco, de I6 de mayo de 2000, Rec. 262/2000, de contraste para la unificación de doctrina en la STS, de 4 de julio de 2006, Rcud. I077/2005.

${ }^{59}$ El cuál será objeto de estudio en el punto siguiente por la extensión y complejidad que presenta.

${ }^{60}$ Sala Franco, T., Pérez Infante, J. I. y López Terrada, E., Las modalidades..., cit.,. I20. Haciendo hincapié en la necesidad de «determinar la concurrencia del fraude» como remarca la doctrina jurisprudencial. 


\section{a) Responsabilidad de la empresa usuaria}

La responsabilidad de la empresa usuaria, como veremos, tiene dos vertientes establecidas en el artículo I6.3 LETT, una de ellas subsidiaria y la otra solidaria, donde, en todo caso, hay que atender a la naturaleza de los contratos de trabajo para establecer el carácter de la misma que ha de operar.

b) Cómputo de la antigüedad

Sin estar recogido expresamente en la legislación laboral ${ }^{6}$, la jurisprudencia ha ido elaborando el régimen necesario para poder realizar el cómputo de la antigüedad en lo referente a la sucesión de contratos temporales por cuanto afecta, entre otros, a la cuantía de la indemnización; a la posibilidad de percibir el plus de antigüedad convencionalmente establecido; a la reclamación de cantidad por los salarios dejados de percibir en los últimos doce meses o a la posibilidad de convertir en indefinida la relación laboral.

En este sentido, la STS, de 29 de mayo de I997, Rcud. 4I49/1996, (FD 2º establece los supuestos para efectuar el control de legalidad sobre el alcance de la antigüedad en el supuesto de la sucesión de contratos y al respecto establece lo siguiente:

«I) si no existe solución de continuidad en la secuencia contractual deben ser examinados todos los contratos sucesivos; 2) si se ha producido una interrupción en la secuencia contractual superior a los veinte días previstos como plazo de caducidad para la acción de despido, entonces sólo procede el examen o control de legalidad de los contratos celebrados con posterioridad; 3) en aplicación de la regla precedente, el control de legalidad se ha de atener exclusivamente al último contrato celebrado cuando entre él y el anterior exista una solución de continuidad superior al plazo de caducidad de la acción de despido y 4) no obstante lo anterior, como se precisa en sentencia de unificación de doctrina de esta misma fecha, cabe el examen judicial de toda la serie contractual, sin atender con precisión aritmética a la duración de las interrupciones entre contratos sucesivos en supuestos singulares y excepcionales en que se acreditan una actuación empresarial en fraude de ley y al mismo tiempo la unidad esencial del vínculo laboral.»

Aunque la STS, de 28 de febrero de 2005, Rcud. I468/2004 supuesto al entender que el trabajo realizado por períodos, mediando interrupciones de más de cuatro meses entre contratos, durante más de una década, no era constitutivo de un único vínculo laboral, si no que se trataba de distintos contratos extinguidos definitivamente contra los que no hubo posibilidad alguna de ejercitar la acción de reclamar por haber transcurrido el plazo de impugnación de veinte días, la posterior STS, de 4 de julio de 2006, Rcud. I077/2005, entendió (FD 6º, aparato cuarto) que «el art. 43 ET (Cesión ilegal de trabajadores) únicamente alcanza a los CPD realizados en supuestos no previstos en la formulación positiva del art. 6 LETT (supuestos de utilización del CPD) y a los contemplados en la formulación negativa de las exclusiones previstas por el art. 8 LETT,

\footnotetext{
${ }^{6 r}$ En este sentido, destacar que la LETT no hace ninguna referencia expresa al cómputo de la antigüedad mientras que el ET sí las hace respecto de los contratos formativos [art. II.I f)]; del período de prueba [art. I4.3]; de la igualdad entre trabajadores indefinidos y temporales [art. 15.6]; de la cesión de trabajadores [art. 43.4] y de los trabajadores en situación de excedencia forzosa [art. 46.I], así como también hace alguna referencia a lo establecido en la negociación colectiva pero no remite, en ningún caso, al cómputo de la antigüedad en la sucesión de contratos temporales.

${ }^{62}$ Sobre la encadenación de contratos en la Sociedad Estatal Correos y Telégrafos S.A. sin mediar la actuación de ninguna ETT.
} 
(exclusiones del CPD) no pareciendo fuera de lugar la afirmación de que en todo caso resultará integrante de cesión ilegal la que lo sea con carácter permanente o para cubrir necesidades permanentes de mano de obra, supuestos en los que el CPD se manifiesta claramente fraudulento e incurso en la previsión del art. 6.4 CC (fraude de ley)» por lo que terminó declarando el despido como improcedente haciendo responsables tanto a la empresa usuaria como a las ETT.

Además, la STS, de 20 de febrero de 1997, Rcud. 2580/1996, ya anunció (FD $3^{\circ}$ ) «que la afirmación de que "en el caso de contrataciones temporales sucesivas el examen de los contratos debe limitarse al último de ellos" es una afirmación que solo podría ser aceptada de modo excepcional, cuando de las series contractuales reflejadas en los hechos probados no se infiere defecto sustancial alguno en los contratos temporales, o fraude de ley.» ${ }^{6364}$

También hemos de tener en cuenta que la simple irregularidad del primero de los

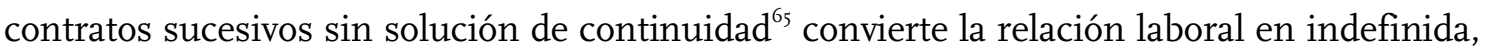
aun cuando los posteriores hayan sido realizados conforme a derecho prevaleciendo la indisponibilidad de derechos según lo establecido en el artículo 3.5 del Estatuto de los Trabajadores ${ }^{66}$.

Aunque dicha irregularidad ha de entenderse siempre con ánimo fraudulento y no como una mera irregularidad formal como podría ser la obligación de realizar determinados contratos en forma escrita, pues entonces operaría lo dispuesto en el artículo 8.2 ET que «de no observarse tal exigencia, el contrato se presumirá celebrado por tiempo indefinido y a jornada completa, salvo prueba en contrario que acredite su naturaleza temporal o el carácter a tiempo parcial de los servicios.» Recayendo eso sí, la carga de la prueba sobre el empleador.

\section{III.I.3. El supuesto del artículo I5.5 del Estatuto de los Trabajadores}

Además de los límites ya comentados en función del tipo de contrato y la doctrina citada sobre el preceptivo control de legalidad que los jueces y tribunales han de efectuar, el artículo I5.5 ET establece que «los trabajadores que en un periodo de treinta meses hubieran estado contratados durante un plazo superior a veinticuatro meses (...) para el mismo o diferente puesto de trabajo con la misma empresa o grupo de empresas, mediante dos o más contratos temporales (...) adquirirán la condición de trabajadores fijos», si bien se

\footnotetext{
${ }^{63}$ Para un estudio más a fondo consultar DANS ÁLVAREZ DE SOTOMAYOR, L., «Sobre la utilización fraudulenta del contrato de puesta a disposición y la responsabilidad de la empresa usuaria en la cesión de trabajadores a través de Empresas de Trabajo Temporal», Anuario da Facultade de Dereito da Universidade da Coruña, I2/2008, que también destaca la importancia del FD $4^{\circ}$ de dicha sentencia (pág. 23I).

${ }^{64} \mathrm{Y}$ en el mismo sentido, la STSJ de Castilla-La Mancha, de I8 de septiembre de 2000 , Rec. $780 / 2000$, se refirió $\left(\mathrm{FD} 4^{\circ}\right.$ ) a la valoración de la verdadera voluntad de las partes [arts. I28I y I282 CC]; al «escaso tiempo transcurrido (4 días) desde que se dice finiquitada, hasta que se firma formalmente el nuevo contrato» y a la utilización fraudulenta del contrato de trabajo, contraria a su finalidad legal [art. 6.4 CC].

${ }^{65}$ Referido al primero de los supuestos de la doctrina citada para efectuar el control de legalidad de la sucesión de contratos.

${ }^{66}$ Así lo señala Sala Franco, T., Pérez Infante, J. I. y LóPez Terrada, E., Las modalidades..., cit., pág. I2i. En todo caso, art. 3.5 ET. «Los trabajadores no podrán disponer válidamente, antes o después de su adquisición, de los derechos que tengan reconocidos por disposiciones legales de derecho necesario. Tampoco podrán disponer válidamente de los derechos reconocidos como indisponibles por convenio colectivo.»
} 
excluye del cómputo los contratos de obra o servicio determinado superiores a veinticuatro meses $^{67}$.

Llegados a este punto, cabe señalar los dos aspectos más problemáticos de este artículo. El primero de ellos, intrínseco a su propia redacción pues hace referencia a la misma empresa o grupo de empresas siendo necesario determinar la amplitud de ambos conceptos y el segundo, derivado de la actuación del legislador al suspender la aplicación de este precepto hasta el 3I de diciembre del año 2012 debiendo esclarecer la posterior aplicación del mismo ${ }^{68}$.

Según se puede leer en la exposición de motivos del RD-Ley Io/20II el legislador justificó esta suspensión porque este precepto «lejos de fomentar la contratación indefinida, puede estar produciendo efectos indeseados de no renovación de contratos temporales y afectando negativamente al mantenimiento del empleo.»

\section{a) Grupo de empresas}

Cuando la norma se refiere a la misma empresa no suscita polémica alguna ${ }^{69}$, si no que esta viene de la expresión grupo de empresas. En las anteriores redacciones de este artículo no existía tal referencia ${ }^{70}$ por lo que las posibilidades de interpretar dicho precepto eran numerosas en función de la diversidad de intereses. Sin embargo, en la actual redacción hay que reseñar cuál es el significado de dicha expresión.

En el Derecho Mercantil, el artículo I8 TRLSC ${ }^{71}$ se remite al supuesto en el que es necesario presentar las cuentas anuales consolidadas recogido en el artículo 42.I del Código de Comercio $^{72}$ que establece que existirá «un grupo cuando una sociedad ostente o pueda ostentar, directa o indirectamente, el control de otra u otras» ${ }^{73}$ y se presumirá dicho control cuando (a) dicha sociedad posea la mayoría de los derechos de voto; (b) controle el órgano de administración bien por ostentar la facultad de nombrar o destituir a sus miembros; (c)

\footnotetext{
${ }^{67}$ Ya que «estos contratos no podrán tener una duración superior a tres años ampliable hasta doce meses más por convenio colectivo» [art. I5.I a) ET] y por sí solos derivarían automáticamente indefinidos, por lo que el propio artículo incluye la expresión «mediante dos o más contratos temporales»

${ }^{68}$ Según lo establecido en el artículo 5 del Real Decreto-ley Io/20II, de 26 de agosto, de medidas urgentes para la promoción del empleo de los jóvenes, el fomento de la estabilidad en el empleo y el mantenimiento del programa de recualificación profesional de las personas que agoten su protección por desempleo. (BOE núm. 208, de 30/08/20II)

${ }^{69}$ Puesto que la empresa empleadora puede identificarse perfectamente por su personalidad jurídica, la cual ostenta un único CIF a efectos tributarios o un Código de Cuenta de Cotización frente a la Seguridad Social.

${ }^{70}$ Al igual que tampoco se hacía referencia al «diferente puesto de trabajo». Redacción actual dada por el artículo I.2 RD-Ley Iо/20Io, de I6 de junio, que las incluye ambas y aclaró un poco la cuestión suscitada por cuanto Sala Franco, T., Pérez Infante, J. I. y López Terrada, E., Las modalidades..., cit., págs. I22 - I23. Ya señaló que, sin haber unificación de doctrina al respecto, existían tres tesis sobre cómo interpretar esta última clausula.

${ }^{71}$ Real Decreto Legislativo I/2010, de 2 de julio, por el que se aprueba el texto refundido de la Ley de Sociedades de Capital, (BOE núm. I6I, de 03/07/2010).

${ }^{72}$ Real Decreto de 22 de agosto de I885, por el que se publica el Código de Comercio. (Gaceta núm. 289, de I6/10/1885).

${ }^{73}$ En la misma línea que el art. 3.I $3^{\circ}$ ) de la Ley ı0/1997, de 24 de abril, sobre derechos de información y consulta de los trabajadores en las empresas y grupos de empresas de dimensión comunitaria (BOE núm. 99, de 25/04/1997): «'Grupo de empresas', el formado por una empresa que ejerce el control y las empresas controladas.»
} 
pueda disponer de la mayoría de los votos en acuerdos con terceros o (d) haya nombrado dentro de los dos años anteriores a dichos miembros.

En el Derecho del Trabajo nos encontramos con que no existe una definición para grupo de empresas ${ }^{74}$ por lo que ha sido el Tribunal Supremo a través de su doctrina el que ha configurado los mecanismos para conocer cuando se da este supuesto. Así pues, además del ámbito de control y propiedad reconocido por el Derecho Mercantil, la STS, de 26 de enero de 1998, Rcud. 2365/1997, dictaminó (FD 2 ${ }^{\circ}$ ) que «no es suficiente que concurra el mero hecho de que dos o más empresas pertenezcan al mismo grupo empresarial» si no que hay que atender a otros elementos para la concurrencia de tal circunstancia como son:

«I.- Funcionamiento unitario de las organizaciones de trabajo de las empresas del grupo. 2.Prestación de trabajo común, simultánea o sucesiva, en favor de varias de las empresas del grupo. 3.Creación de empresas aparentes sin sustento real, determinantes de una exclusión de responsabilidades laborales 4.- Confusión de plantillas, confusión de patrimonios, apariencia externa de unidad empresarial y unidad de dirección.»

De este modo, tal y como señala dicha sentencia, cuando se determine la existencia del grupo de empresas, se declarará la responsabilidad solidaria respecto de las obligaciones contraídas por cada una de ellas. Por lo que se desprende que dicha responsabilidad opera en el momento en el que el grupo de empresas actúa como una sola entidad, intercambiando recursos y/o personal o cuando se aprecie una conducta fraudulenta en lo que a las relaciones laborales se refiere. Por el contrario, mientras las empresas del mismo grupo actúen como entidades autónomas, aun existiendo tal concurrencia de control y propiedad, no será de apreciar la misma.

b) Suspensión temporal tras la reforma del año 2OII

Si bien el artículo 5 del RD-Ley Io/20II fijó el 3I de agosto de 2013 como fecha clave hasta la cual perduraría la suspensión de dicho precepto, una ulterior revisión ${ }^{75}$ estableció el 3 I de diciembre de 2012 como referencia definitiva. Lo cual, tras los períodos de veinticuatro y treinta meses que establece el artículo objeto de estudio, nos sitúa en un momento temporal en el que pueden ser objeto de revisión los contratos de trabajo realizados en la segunda mitad del año 20Io. Esto es así porque esta última modificación legislativa señaló que durante el período de suspensión, el mismo no computara en ambos períodos de referencia ${ }^{76}$ por lo que la revisión que pueda surgir al período previo a esta suspensión irá caducando progresivamente y no desaparecerá definitivamente hasta el i de julio de 2015 .

${ }^{74}$ Reconocido así por la STSJ de Madrid, de 25 de mayo de 20I2, Rec. I58I/20I2 (FD 6º).

${ }^{75}$ Art. I7.I Real Decreto-ley 3/2012, de Io de febrero, de medidas urgentes para la reforma del mercado laboral. (BOE núm. 36, de II/O2/20I2) «Se suspende, hasta el 3I de diciembre de 20I2, la aplicación de lo dispuesto en el artículo 15.5 del Texto Refundido de la Ley del Estatuto de los Trabajadores, aprobado por Real Decreto Legislativo I/I995, de 24 de marzo.»

${ }^{76}$ Art. I7.2 RD-Ley 3/20I2 «A los efectos de lo establecido en el apartado anterior, quedará excluido del cómputo del plazo de veinticuatro meses y del periodo de treinta a que se refiere el artículo I5.5 del Estatuto de los Trabajadores, el tiempo transcurrido entre el 3I de agosto de 20 II y el 3I de diciembre de 20I2, haya existido o no prestación de servicios por el trabajador entre dichas fechas, computándose en todo caso a los efectos de lo indicado en dicho artículo los periodos de servicios transcurridos, respectivamente, con anterioridad o posterioridad a las mismas.» 
En todo caso, la suspensión temporal del citado artículo I5.5 ET no supuso la inaplicación del resto de las reglas de los contratos de trabajo, por lo que se tendrá que seguir acreditando la eventualidad de dichos contratos ${ }^{77}$.

III.I.4. Cláusula de prohibición de contratación del trabajador por la empresa usuaria

Asiduamente las empresas concurren a los servicios de las Empresas de Trabajo Temporal para que estas realicen el proceso de selección de las nuevas incorporaciones ${ }^{78}$ y así aprovechar la duración de tal contratación para conocer el desempeño y valía de los posibles aspirantes.

Por otro lado, la legalización de las ETT fue una respuesta a las necesidades coyunturales para dinamizar el mercado de trabajo e intentar coordinar la oferta y demanda del mismo, por lo que dichas ETT no pueden suponer un obstáculo a dicho mercado y es por ello que el artículo 7.3 LETT, que se mantiene en los mismos términos que en su redacción original, establece como «nula la cláusula del contrato de puesta a disposición que prohíba la contratación del trabajador por la empresa usuaria a la finalización del contrato de puesta a disposición.»

\section{III.3. Responsabilidad contractual}

Aunando en un solo punto la responsabilidad contractual derivada tras la extinción del CPD debemos acudir tanto a la legislación, como a la jurisprudencia, para señalar todas aquellas situaciones que convierten en indefinidas estas relaciones laborales, donde cabe señalar las siguientes tres:

El trabajador que tras la finalización del CPD continúe prestando servicios en la empresa usuaria «se considerará vinculado a la misma por un contrato indefinido» [art. 7.2 LETT]. Este supuesto hay que entenderlo cuando la prestación de servicios continúe al margen de un nuevo contrato de trabajo ${ }^{79}$ eximiendo de responsabilidad a la ETT al encontrarnos ante un supuesto de novación extintiva ${ }^{80 \mathrm{81}}$.

- También se presumirán como indefinidos los contratos temporales celebrados en fraude de ley [arts. I5.3 ET y $6.4 \mathrm{CC}$ ], o lo que es lo mismo, aquellos que tomen una

77 Ortega Figueiral, E. «Sucesión contractual: nueva vigencia del artículo I5.5 del Estatuto de los Trabajadores» (disponible en http://eduardortega.blogcanalprofesional.es/sucesion-contractual-nueva-vigenciadel-articulo-I5-5-del-estatuto-de-los-trabajadores/; fecha de consulta: 30/05/20I4) al señalar las campañas de control que la propia ITSS llevó a cabo y la imposibilidad de los empleadores de justificar hasta 24 meses de eventualidad.

\footnotetext{
${ }_{78}$ Determinadas empresas no quieren o no pueden asumir los costes relativos a la realización de un proceso de selección por lo que fían a los servicios y estructura de las ETT por el acceso rápido y fácil que estas tienen sobre numerosos trabajadores.

${ }^{79}$ VALDÉs DAL-RÉ, F., «Contrato...», cit., págs. 238 y ss.

${ }^{80}$ Ibíd., pág. 239.

${ }^{8}$ Tampoco cabe olvidar lo expuesto en el punto 3.I.2. sobre que el contrato se considere prorrogado tácitamente hasta la duración máxima permitida o salvo que se acredite la naturaleza temporal del mismo.
} 
forma diferente del que pretendan eludir. En el mismo sentido, cuando esta contratación se realiza mediando una ETT nos encontramos ante el supuesto de cesión ilegal de trabajadores [art. 43.2 ET] como ya señalamos citando la STS, de 4 de julio de 2006 , Rcud. I077/2005, (FD 6\%).

- Si bien el supuesto anterior se puede entender respecto del objeto y su naturaleza, el artículo i5 del estatuto en sus apartados i (letras a y b) y 5 establece la limitación temporal que pueden ostentar los contratos, presumiéndose también celebrados en fraude de ley los que incumplan tales obligaciones.

Salvo el primer caso en que el trabajador se considerará vinculado a la empresa usuaria, en los dos restantes, cuando se aprecia el fraude de ley, el trabajador podrá optar por la empresa cedente o cesionaria para adquirir la condición de trabajadores fijos en igualdad de condiciones a un trabajador que presta servicios en un puesto de trabajo o equivalente [art. $43 \cdot 4 \mathrm{ET}]$.

\section{III.4. Responsabilidad económica}

Junto a esta responsabilidad contractual, analizada en el epígrafe anterior, también puede surgir otra de carácter económico, bien sea de tipo salarial, indemnizatoria o administrativa. En principio, esta responsabilidad económica tiene para el trabajador las mismas garantías legales que las de las relaciones de trabajo ordinarias, salvo con alguna particularidad concerniente a la relación triangular como es el régimen establecido a la hora de dirimir la responsabilidad entre las empresas cedentes o cesionarias.

\section{III.3.I. Régimen de la responsabilidad económica}

Respecto del régimen de la responsabilidad económica vamos a estudiar las dos vertientes totalmente diferentes, principalmente por la traslación a terceros que puedan ocasionar. La primera de ellas es la referente a la responsabilidad frente a las administraciones públicas $y$, la segunda, referida a la responsabilidad frente a los trabajadores puestos a disposición.

a) Responsabilidad frente a las administraciones públicas

Aunque del hecho de la extinción del contrato de trabajo no nace ninguna responsabilidad administrativa, es importante hacer referencia a esta para destacar que respecto de las sanciones impuestas por la Autoridad Laboral competente no cabe ni derivarla a terceros ni asegurarla, pues estamos ante un supuesto de responsabilidad directa. El régimen sancionador sobre la cesión de trabajadores está recogido en la Sección $4^{a}$ del Capítulo II de la LISOS y en materia de cesión trasnacional en el Capítulo VI de la LETT.

b) Responsabilidad frente a los trabajadores

Debido a la pluralidad de los empresarios implicados y para evitar que éstos eludan sus obligaciones salariales y de Seguridad Social se ha establecido un régimen de carácter preventivo-disuasorio $^{{ }_{2}}$. El mismo descansa sobre la obligación de la ETT de constituir una garantía financiera y sobre los dos tipos de responsabilidades recogidas en el artículo I6.3

${ }^{82}$ Moreno Vida, M. N., El trabajo..., cit., pág. 86. 
LETT, donde la primera de ellas es en régimen de subsidiariedad de la empresa usuaria respecto de la ETT, el segundo tipo al que nos referimos es a la responsabilidad solidaria cuando el CPD se haya realizado «incumpliendo lo dispuesto en los artículos 6 y 8 (LETT) $\gg^{8_{3}} \mathrm{y}$, aunque la ley no lo recoge expresamente, esta responsabilidad solidaria también tendrá cabida sobre todas ellas cuando en la contratación fraudulenta hayan participado varias empresas de trabajo tempora ${ }^{84}$. En ambos casos la responsabilidad recaerá sobre las obligaciones salariales y de Seguridad Social, así como de las indemnizaciones derivadas de la extinción del contrato de trabajo.

Como norma general, la responsabilidad inicial de la empresa usuaria es subsidiaria y sólo entrará en juego cuando la ETT no pueda hacer frente a sus obligaciones salariales, indemnizatorias o de Seguridad Social.

Cuando del CPD se derive la responsabilidad solidaria no se podrá minorar la responsabilidad de las partes por la necesidad de garantizar los derechos de los trabajadores, pues si bien la ETT es la empleadora se entiende que la empresa usuaria es también beneficiaria de los servicios desempeñados por el trabajador ${ }^{85}$.

\section{III.3.2. La garantía financiera de las Empresas de Trabajo Temporal}

Las Empresas de Trabajo Temporal están obligadas a constituir una garantía financiera y ponerla a disposición de la Autoridad Laboral para hacer frente a los posibles impagos frente a los trabajadores en cuestión de salarios, indemnizaciones y cuotas de la Seguridad Social que se deriven del Contrato de Puesta a Disposición [art. 3 LETT].

En el primer ejercicio de actividad de la ETT la garantía ascenderá a veinticinco veces el SMI en cómputo anual y los sucesivos al diez por cien de la masa salarial del ejercicio inmediatamente anterior, sin poder ser inferior a la cantidad constituida para el primero. Además, la ETT tendrá que actualizar cada ejercicio el importe de dicha garantía y acreditarlo ante la Autoridad Laboral en los tres primeros meses del año [art. 7 RLETT $^{86}$ ].

El trabajador podrá solicitar a la Autoridad Laboral la ejecución de la garantía financiera cuando concurra la situación de insolvencia, suspensión de pagos, quiebra o concurso de acreedores siempre y cuando las deudas por salarios, indemnizaciones o cuotas de Seguridad Social hayan sido reconocidas en acto de conciliación, resolución judicial firme o certificación de descubierto de la propia TGSS según lo dispuesto en el artículo 9 RLETT.

El trabajador dispone del plazo de un año para solicitar la ejecución de la garantía financiera a contar desde que la deuda fuera reconocida, bien por resolución judicial firme o en el propio acto de conciliación.

\footnotetext{
${ }^{83}$ Cabe recordar el inciso que se viene haciendo en este trabajo sobre la concurrencia de la contratación fraudulenta al incurrir en la cesión ilegal de trabajadores. En este mismo sentido, el artículo 43.3 ET establece que «Los empresarios, cedente y cesionario, que infrinjan lo señalado en los apartados anteriores (sobre la cesión de trabajadores) responderán solidariamente de las obligaciones contraídas con los trabajadores y con la Seguridad Social, sin perjuicio de las demás responsabilidades, incluso penales, que procedan por dichos actos.»

${ }^{84}$ Así lo puso de manifiesto la STS, de 4 de julio de 2006, Rcud. I077/2005, en su FD 6ª aparato cuarto.

${ }^{85} \mathrm{STS}$, de 4 de julio de 2006, Rcud. I077/2005, (FD $\left.3^{\circ}\right)$.

${ }^{86}$ Real Decreto 4/1995, de I3 de enero, por el que se desarrolla la Ley I4/1994, de I de junio, por la que se regulan las empresas de trabajo temporal (BOE núm. 27, de or/02/1995).
} 
Debido a que la garantía sirve para hacer frente al impago de distintos conceptos el reglamento, en su artículo 9.4, establece la prelación de los mismos de tal forma que los salarios gozan de mayor preferencia que las indemnizaciones y estas a su vez sobre las cuotas a la Seguridad Social y otros conceptos de recaudación conjunta. En todo caso, dentro de los salarios, tendrán preferencia absoluta los correspondientes a los últimos treinta días de trabajo cuya cuantía no supere el doble del SMI y para los restantes la prelación se determinará en orden a la fecha en que se solicite la ejecución.

\section{III.3.3. Responsabilidad salarial}

Este tipo de responsabilidad deriva de los salarios dejaros de percibir por el trabajador durante la vigencia de la relación laboral. En lo referente a la cuantía y los plazos de caducidad presenta exactamente las mismas condiciones que las relaciones de trabajo $\operatorname{ordinarias}^{87}$. Si bien hay que atender a la especialidad de que estamos hablando de una relación triangular, motivo por el cual se ha optado por dotar con mayores garantías para asegurar el cobro de dichos salarios, siendo responsables tanto la ETT como la empresa usuaria, en función de la responsabilidad que se le otorgue a esta, y en última instancia el Fondo de Garantía Salarial conforme al artículo 33 del Estatuto de los Trabajadores ${ }^{88}$.

Cabe señalar, eso sí, que para que concurra este último supuesto es necesario que las indemnizaciones hayan sido reconocidas como consecuencia de sentencia, auto, acto de conciliación judicial o resolución administrativa sin poder superar el doble del SMI en el cálculo de su base diaria por un máximo de 120 días $^{89}$.

En todo caso, el plazo para reclamar los salarios dejados de percibir es de un año desde el día en que la acción pueda ejercitarse [art. 59 ET], idéntico plazo para efectuar la reclamación para la ejecución de la garantía financiera de la ETT.

\section{III.3.4. Responsabilidad indemnizatoria}

Las posibilidades para solicitar la indemnización son numerosas, así que nos encontramos con la indemnización correspondiente a la finalización del contrato de trabajo y la derivada por despido. La cuantía de ambas dos puede variar de tal forma hasta que en determinados supuestos siquiera concurra derecho a la misma. Además, también hay que tener en cuenta la forma en que se computa la base diaria sobre la cual se establece la indemnización final.

\footnotetext{
${ }^{87}$ Artículo 6.2 LETT «Podrán celebrarse contratos de puesta a disposición entre una empresa de trabajo temporal y una empresa usuaria en los mismos supuestos y bajo las mismas condiciones y requisitos en que la empresa usuaria podría celebrar un contrato de duración determinada...» en concordancia con la Directiva europea y el principio de igualdad.

${ }^{88}$ FOGASA abonará a los trabajadores el importe de los salarios pendientes de pago a causa de insolvencia o concurso del empresario [art. 33.I ET] y tal derecho prescribirá al año de la fecha del acto de conciliación, sentencia, auto o resolución de la Autoridad Laboral en que se reconozca la deuda por salarios o se fijen las indemnizaciones [art. 33.7 ET].

${ }^{89}$ El artículo I9 del Real Decreto-ley 20/20I2, de I3 de julio, de medidas para garantizar la estabilidad presupuestaria y de fomento de la competitividad (BOE núm. I68, de I4/07/20I2), modificó a la baja la cantidad abonada por FOGASA. Anteriormente, FOGASA se hacía cargo de una cuantía similar al triple del SMI en un período igual al año. STS, de 3I de enero de 2008, Rcud. 3863/2006, citada en MERCAdER UGUiNA, J. R. (dir.), ORTIZ Lallana, C. (coord.) et al., Despido y extinción del contrato de trabajo en la doctrina judicial. Una perspectiva para la reforma laboral, Valladolid, Lex Nova, 20ı0, pág. 256.
} 
Aun con todo esto, hay que destacar que mediante la negociación colectiva cabe la posibilidad de mejorar las indemnizaciones, tanto la correspondiente a la finalización de contrato $^{9 \circ}$, como la derivada del despido, a fin de proteger el empleo.

a) Indemnización por finalización del contrato de trabajo

La indemnización a la que tienen derecho los trabajadores a la finalización del contrato hay que contemplarla desde el Estatuto de los Trabajadores y lo dispuesto en la negociación colectiva. Como regla general, cabe señalar que se ha establecido una indemnización de doce días de salario por cada año de servicio o de la parte proporcional en los períodos inferiores al año [art. 49.I c) ET], si bien es necesario puntualizar.

En primer lugar, dicha indemnización no se empezará a abonar integra hasta el año 2015 pues nos encontramos dentro de un período de transición de cuatro años (20II-20I4 inclusive) en el que se está aumentando progresiva y anualmente un día de indemnización por año de servicio ${ }^{91}$.

Respecto de lo anterior, la indemnización se aplica en función del ejercicio en que se celebró el contrato de trabajo y no sobre el año en que este finalice. En el caso de formalizar una prórroga hay que destacar que se sigue manteniendo la unidad del contrato, aunque esta tenga alcance o se firme en el ejercicio posterior, por lo que como fecha de referencia se sigue manteniendo el año de celebración del contrato.

Por último, cabe señalar que hay dos modalidades contractuales que no generan este derecho en su finalización y son el contrato de interinidad y los contratos formativos [art. 49.I c) ET]. Importante dato por cuanto el contrato de interinidad se ha venido utilizando por las empresas para la sustitución de los trabajadores en período de vacaciones cuando para esta situación la jurisprudencia dictaminó que ha de emplearse el contrato eventual por circunstancias de la producción debido a un descenso de la plantilla efectiva ${ }^{92}$.

\section{b) Indemnización por despido}

Respecto de la indemnización por despido la cuantía también variará en función de la situación en el que este se produzca y la declaración judicial obtenida. Centrándonos en las principales vías que tiene la ETT, actuando como empleador principal, para fundamentar el despido de un trabajador debemos destacar el despido por causas objetivas y el despido disciplinario [arts. 52 y 54 ET].

Cuando el despido por causas objetivas sea declarado procedente corresponderá al trabajador percibir una indemnización de veinte días por año de servicio con un máximo de doce mensualidades, si por el contrario, ha sido declarado improcedente corresponderá la

\footnotetext{
${ }^{9 \circ}$ Este supuesto de mejora de las indemnizaciones en las relaciones de trabajo temporales persigue la idea de que cuanto más se penalicen y/o equiparen a las indemnizaciones de las relaciones indefinidas, menor uso se hará de las primeras.

${ }^{91}$ La Disp. Transitoria decimotercera del ET establece que la indemnización establecida para la finalización de los contratos temporales será de ocho días para los celebrados hasta el 3i de diciembre del año 20ir; 9 días para los celebrados en 20I2; Io días en 20I3; II días en 2014 y I2 días a partir del i de enero del año 2015.

${ }^{92}$ STS, de 12 de junio de 20I2, Rcud.3375/20II, (FD $2^{\circ}$ ).
} 
cuantía equivalente a treinta y tres días por año de servicio con un máximo de veinticuatro mensualidades ${ }^{93}$.

En el caso del despido disciplinario, la procedencia del despido no generará indemnización alguna [art. 55.7 ET] y si fuera declarado improcedente dará lugar a la misma indemnización que en el supuesto anterior, treinta y tres días por año de servicio con un máximo de veinticuatro mensualidades ${ }^{94}$.

En ambos caso, la indemnización por la improcedencia del despido el empresario podrá optar sustituir la indemnización por la readmisión en el puesto de trabajo [arts. 53.5 b) y 56.I ET]. Opción esta no siempre viable pues choca con la principal característica de estas relaciones de trabajo, que es la temporalidad, al poder exceder el pronunciamiento judicial la fecha de finalización del contrato.

También cabe la posibilidad de que el despido sea declarado nulo cuando concurran causas de discriminación prohibidas o se vulneren situaciones especialmente protegidas [art. 53.4 ET] produciendo la readmisión inmediata del trabajador, con abono de los salarios dejados de percibir [art. 55.6 ET].

c) Cálculo de la base diaria

La cuantía de la indemnización se determina por días por año de servicio con un límite que no se puede rebasar, lo cual suscita distintas interpretaciones más o menos restrictivas en función de los intereses que se defiendan. La jurisprudencia ha entendido ${ }^{95}$ que para hallar la base diaria será necesario dividir entre 365 (366 si se tratara de año bisiesto) la suma de los conceptos salariales [art. 26 ET] de las I2 nóminas anteriores. Si la relación laboral fuese menor del año, algo factible al tratarse de trabajadores temporales, se utilizarán los días reales de los meses concretos y no los ficticios treinta. Para cuantificar los años de servicio, los años enteros contarán como tal, mientras que las fracciones se entenderán como meses completos (I/I2, 2/ז2...) y los días sobrantes computarán como un mes más ${ }^{96}$.

Por último, respecto de la antigüedad, hemos reseñado el modo en que ha entendido la jurisprudencia tal circunstancia destacando la posibilidad de poder computar desde el contrato que inició de la relación laboral cuando la misma haya sido fraudulenta.

\section{III.3.5. Responsabilidad de cuotas de Seguridad Social}

La responsabilidad a la que hace referencia el artículo I6.3 LETT sobre las obligaciones de Seguridad Social se extiende tanto a los actos de cotización como a los de alta

\footnotetext{
${ }^{93}$ Siempre y cuando el contrato de trabajo haya sido celebrado con posterioridad al i2 de febrero de 20I2. En los contratos celebrados con anterioridad a esta fecha, la cuantía de la indemnización equivaldrá, hasta el mismo I2 de febrero, a cuarenta y cinco días por año de servicio con un máximo de cuarenta y dos mensualidades y con posterioridad a la misma a treinta y tres días por año de servicio con un máximo de cuarenta y dos mensualidades según la Disp. transitoria quinta del RD-Ley 3/20I2.

${ }^{94}$ Supuesto idéntico al anterior, también recogido en la Disp. Transitoria quinta del RD-Ley 3/20I2.

${ }^{95} \mathrm{STS}$, de 24 de enero de $201 \mathrm{I}$, Rcud. 20I8/20IO, (FD $5^{\circ}$ ). Interesante interpretación por la incidencia que tiene sobre los trabajadores con modificaciones de jornada o que trabajan con jornadas irregulares que puedan verse alteradas por cuestiones organizativas o de producción.

${ }^{96}$ STS, de 3I de octubre de 2007 , Rec. 4I8I/2006, (FD 2 ${ }^{\circ}$ ).
} 
y afiliación, respondiendo la empresa usuaria en el mismo sentido que de las obligaciones salariales.

En este sentido, la extinción del contrato no produce otros derechos como el de la percepción de una indemnización por fin de contrato o despido, pero es interesante tenerla presente pues la baja en el sistema de la Seguridad Social supone el fin de dichas obligaciones, cuyos efectos pueden prorrogarse en el tiempo pues el plazo de prescripción es de cuatro años [art. 22.I LGSS ${ }^{97}$ y art. 42 .I RD I4I $5 / 2004^{98}$ ].

Cabe diferenciar el incumplimiento de la ETT en el alta o afiliación del trabajador al sistema, de la omisión del pago de cuotas de la Seguridad Social. En el primer supuesto, además de omitir el segundo, pues es requisito indispensable estar incluido en el sistema para poder efectuar la cotización correspondiente, las empresa cedente y cesionaria responderán de aquellas prestaciones sea cual sea su naturaleza que puedan derivarse de la relación laboral ${ }^{99}$, pues en esta situación el trabajador se encuentra en situación de alta presunta [art. I25.3 LGSS].

En el otro supuesto, cuando el incumplimiento derive de la obligación de efectuar la cotización, dependerá de la gravedad del hecho para dirimir responsabilidades. Provocará la responsabilidad directa de la ETT -y la consecuente en la empresa usuaria- los incumplimientos que pretendan eludir la obligación de cotizar; la reiteración en los impagos o los que provoquen un descubierto en el trabajador que le impida tener acceso a la prestación correspondiente. Por otro lado, no acarrearán responsabilidad en el pago de las prestaciones cuando el incumplimiento haya sido ocasional o por cotizar en una cuantía menor ${ }^{\text {10o }}$.

Además del pago de las prestaciones, estos incumplimientos también estarán sujetos a los recargos [arts. 27 LGSS y Io RD I4I5/2004]; intereses de demora [arts. 28 LGSS y II RD I4I5/2004] así como de la responsabilidad administrativa conforme a la LISOS.

\section{Otras consideraciones}

Además de lo expuesto durante este trabajo hay algunos aspectos que deben quedar reflejados por cuanto resultan interesantes dentro del marco de la cesión de trabajadores.

Si bien este es un tema muy amplio para su estudio, estas dos consideraciones son especialmente relevantes tras la extinción de la relación laboral. Una de ellas por cuanto concierne a la representación de los trabajadores y el trabajador cedido y la otra por acaparar la responsabilidad de las Administraciones Públicas, una vez que están habilitadas para externalizar parte de su trabajo mediante las Empresas de Trabajo Temporal.

${ }^{97}$ Real Decreto Legislativo I/I994, de 20 de junio, por el que se aprueba el Texto Refundido de la Ley General de la Seguridad Social (BOE núm. I54, de 29/06/1994).

${ }^{98}$ Real Decreto I4I5/2004, de II de junio, por el que se aprueba el Reglamento General de Recaudación de la Seguridad Social (BOE núm. I53, de 25/06/2004).

99 Gala Durán, C., «Responsabilidades laborales y de Seguridad Social», en Molero Marañón, M. L. y VALDÉs DAL-RÉ, F. (dirs.), Comentarios a la Ley de Empresas de Trabajo Temporal, cit., págs. 569 y ss., expone las distintas combinaciones que pueden darse en cuanto la prestación derive de contingencias comunes, profesionales o de otras situaciones recogidas como riesgo durante el embarazo o lactancia.

${ }^{100}$ Ibíd., págs. 569 y ss. 


\section{IV.I. Representación de los trabajadores en la empresa usuaria}

Aunque el trabajador cedido es un empleado de la ETT hay que tener presente el hecho de que el trabajo lo presta en la empresa usuaria bajo su dirección. Es por ello que los representantes de los trabajadores tienen atribuida la representación de los trabajadores en misión en cuanto a la ejecución del trabajo o de sus condiciones se refiera.

De lo expuesto, en relación con la igualdad de condiciones entre los trabajadores de la empresa usuaria y los cedidos, la LETT se remite entre otras a la utilización del transporte o de las instalaciones; a la información sobre las vacantes o a las medidas de acceso a la formación [art. I7.2; .3 y .4 respectivamente], quedando excluidas, eso sí, la representación de las reclamaciones respecto de la ETT de la cual dependa [art. I7.2].

IV.2. La responsabilidad de las Administraciones Públicas

Este trabajo se ha centrado en el estudio de la responsabilidad derivada de la relación triangular entre ETT, empresa usuaria y trabajador, en este punto se pretende exponer las peculiaridades existentes en materia de cesión de trabajadores a las Administraciones Públicas.

Así pues, la Directiva levantó casi todas las restricciones existentes sobre la cesión de trabajadores salvo las amparadas por el interés general suprimiendo el legislador en su transposición al Derecho nacional las limitaciones en esta fórmula de empleo con las Administraciones Púbicas [Disp. Adicional cuarta LETT].

Además de los límites y exclusiones ya estudiados la misma disposición añade que las ETT «no podrán realizar (cesión de trabajadores) con las Administraciones Públicas para la realización de tareas que, por una norma con rango de Ley, estén reservadas a los funcionarios públicos.» Siendo necesario interpretar este precepto acudiendo a las funciones de los funcionarios de carrera [art. 9.2 $\mathrm{EBEP}^{\mathrm{ror}}$ ]; a lo dispuesto sobre el personal laboral fijo [art. II EBEP] y a la relación de puestos de trabajo que tenga cada administración $^{\text {ro2 }}$ entre otros, para poder determinar el supuesto de contratación fraudulenta.

En caso de concurrir esta contratación fraudulenta, los trabajadores cedidos ilegalmente se consideran vinculados a la empresa con un contrato indefinido. Bien pues, en el caso de las Administraciones Públicas, ha señalado la jurisprudencia que esta no puede suponer una forma de acceso a la función pública, por contravenir los principios de mérito y capacidad, quedando el trabajador en una situación de indefinido no fijo hasta que la propia administración realice la provisión de la plaza ${ }^{\text {ro3 }}$.

\footnotetext{
${ }^{\text {ror }}$ Ley 7/2007, de I2 de abril, del Estatuto Básico del Empleado Público (BOE núm. 89, de I3/04/2007)

${ }^{102}$ Pérez de los Cobos Orihuel, F., «La contratación de trabajadores a través de empresas de trabajo temporal en las Administraciones Públicas», Diario La Ley, 7588, i4 de marzo de 201 .

${ }^{103}$ STS, de 2I de julio de 2008, Rcud. 2I2I/2007, (FD $3^{\circ}$ ).
} 


\section{Conclusiones}

Veinte años después de que se aprobara y entrara en vigor la LETT, se ha puesto de manifiesto que la regulación acerca del objeto de estudio de este trabajo está bien definida. Si bien es cierto que existen determinadas carencias en la legislación por la imposibilidad de recoger toda la diversidad casuística, también lo es que ha sido la propia jurisprudencia la encargada de ir elaborando y construyendo las distintas interpretaciones en base al iter legislativo de las relaciones de trabajo ordinarias.

Esto es así porque aunque la relación laboral surja a partir de un contrato de naturaleza estrictamente mercantil, no podemos obviar el hecho de que el objeto del mismo es una relación laboral por cuenta ajena bajo la fórmula de la cesión de trabajadores, con la particularidad de que el servicio se desempeña en un centro de trabajo y bajo la dirección ajena al empleador titular de dicha relación.

Es por esto último y para proteger los derechos fundamentales más básicos de los trabajadores como son el derecho a preservar la integridad física [arts. I5 CE y 4.2 d) ET], para garantizar el cumplimiento de la normativa sobre seguridad y salud en el trabajo, y para permitir el libre ejercicio del derecho de huelga [arts. 28.2 CE y 4.I e) ET], por lo que dicha ley prevé, entre otros, los supuestos de exclusión ya analizados.

Dicha regulación dota a las partes implicadas en la relación triangular de los instrumentos necesarios para proteger sus intereses, bien sea posibilitar la cesión legal de trabajadores como actividad empresarial, adecuar las necesidades de flexibilidad y de mano de obra a la producción o preservar los derechos del trabajador, pero cabe recordar que dicha relación es de carácter temporal, lo cual deja en una posición de gran vulnerabilidad al trabajador y es entonces por ello por lo que el papel de las organizaciones sindicales ha de ser clave, debiendo llevar con iniciativa propia la defensa de los derechos laborales de los trabajadores cedidos. No sólo en lo referente a una defensa técnico-jurídica, si no dar cobertura a otros derechos como el de formación o información de las condiciones de trabajo y de las vacantes que puedan surgir en la empresa usuaria.

Esto es necesario pues los trabajadores temporales y los cedidos por ETT son un colectivo en auge ligado a la precarización de los puestos de trabajo por ir contra el principio de estabilidad en el empleo. Principio del que pueden desprenderse efectos negativos derivados de la utilización de estos trabajadores, indistintamente de si están, o no, cedidos. Entre estos efectos negativos cabe destacar el ahorro en la masa salarial que produce en el empresario.

Ahorro que bien puede considerarse positivo por beneficiar la viabilidad y competitividad del centro de trabajo, también puede significar una competencia desleal entre trabajadores por cuanto la utilización de los temporales puede suponer la imposibilidad de competir en las mismas condiciones por el trabajo. Esto es así porque, al margen de que se garanticen las mismas condiciones laborales, pues en la norma está consagrado el principio de igualdad, los nuevos trabajadores no podrán consolidar derechos reconocidos en la negociación colectiva por razón de la antigüedad. Derechos, por otra parte, que son indisponibles [art. 3.5 ET] precisamente para evitar la pugna a la baja por el puesto de trabajo. 
También cabe reseñar la importancia de una adecuada redacción de los contratos de trabajo para ajustarlos tanto a la realidad productiva y necesidades de las empresas usuarias, como a la exigencia legal debida, pues como hemos señalado durante este estudio los errores y consecuencias derivadas juegan en contra de los intereses empresariales por cuanto se establece la conversión automática en indefinida de la relación laboral; indemnizaciones por despidos y responsabilidades de tipo administrativa e incluso penal y, en todo caso, hablamos de responsabilidad subsidiaria y solidaria.

Por último, si bien es cierto que las relaciones de trabajo amparadas bajo los Contratos de Puesta a Disposición y su extinción están recogidas en la legislación y en la jurisprudencia consolidada, también lo es que dicha regulación es amplia y diversa, además de estar sometida a constante evolución por lo que se hace imprescindible contar con personal cualificado para que las empresas, tanto las cedentes como las cesionarias, puedan realizar una adecuada gestión sociolaboral. 